\title{
BMJ Open Impact of prenatal diagnosis on survival of newborns with four congenital heart defects: a prospective, population-based cohort study in France (the EPICARD Study)
}

\author{
Babak Khoshnood, ${ }^{1}$ Nathalie Lelong, Lucile Houyel, ${ }^{2}$ Damien Bonnet, ${ }^{3}$ \\ Morgane Ballon, ${ }^{1}$ Jean-Marie Jouannic, ${ }^{4}$ François Goffinet,,${ }^{1,5}$ the EPICARD Study \\ group
}

To cite: Khoshnood B, Lelong N, Houyel L, et al. Impact of prenatal diagnosis on survival of newborns with four congenital heart defects: a prospective, population-based cohort study in France (the EPICARD Study). BMJ Open 2017;7:e018285. doi:10.1136/ bmjopen-2017-018285

- Prepublication history for this paper is available online. To view these files, please visit the journal online (http://dx.doi. org/10.1136/bmjopen-2017018285).

Received 19 June 2017

Revised 8 September 2017

Accepted 15 September 2017

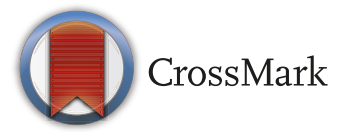

For numbered affiliations see end of article.

Correspondence to Dr Babak Khoshnood; babak.khoshnood@inserm.fr

\section{ABSTRACT}

Objectives (1) Assess the population-level probability of prenatal diagnosis and termination of pregnancy for fetal anomaly for four major congenital heart defects; (2) Examine, using population-based data, the relation between timing of (prenatal vs postnatal) diagnosis and risk of infant (ie, $<1$ year) mortality for four major congenital heart defects (CHDs).

Design Population-based cohort (the EPIdémiologie des CARDiopathies congénitales) study.

Setting Greater Paris area (Paris and its surrounding suburbs).

Patients Three hundred and fifty-four cases of four major CHDs, including functionally univentricular heart (FUH, $\mathrm{N}=132$ ), d-transposition of great arteries ( $d-T G A, N=85$ ), tetralogy of Fallot (TOF, N=60) and coarctation of aorta (CoA, $N=77$ ). Statistical analysis included the MantelHaenszel method and a test of homogeneity of risk ratios. Results Approximately $95 \%$ of FUH, more than twothirds of d-TGA and TOF, and $40 \%$ of CoA were prenatally diagnosed. Overall, we did not find any statistically significant association between timing of (prenatal vs postnatal) diagnosis of CHD and risk of infant mortality (Mantel-Haenszel risk ratio 1.1, 95\% $\mathrm{Cl} 0.5-2.7$ ); and the differences between the risk ratios of the association between prenatal diagnosis and infant mortality across the four CHDs was not statistically significant.

Conclusion These results imply that at least in the settings where specialised services are readily available, survival may no longer be the most relevant outcome, or the best criterion, for evaluating the impact of prenatal diagnosis on the outcome of CHD. The beneficial effects of prenatal diagnosis may be better sought by looking at more 'subtle' or long-term neurodevelopmental outcomes.

\section{INTRODUCTION}

Congenital heart defects (CHDs) are the most frequent group of congenital anomalies. ${ }^{1}$ In addition to their relatively high prevalence ( $\sim 1 \%$ of all births), CHDs also represent an important group of anomalies in that they
Strengths and limitations of this study

- We used data from a large, population-based, prospective cohort study to look at the association between prenatal diagnosis and the risk of infant ( $<1$ year) mortality for newborns with four major congenital heart defects (CHDs): functionally univentricular heart, d-transposition of great arteries, tetralogy of Fallot and coarctation of aorta.

- We looked at both specific effects that may be associated with the four CHDs in our study, as well as, the overall effect. We included a test of homogeneity to assess whether there were significant differences in the relation between prenatal diagnosis and risk of infant mortality for the four CHDs.

- We did not evaluate the effects of prenatal diagnosis on pathways of care or on outcomes other than mortality.

- While data were from a large, population-based prospective cohort study, the number of cases for individual CHDs may not have been adequate to detect relatively small changes associated with prenatal diagnosis for individual CHDs.

- The extent to which our results may be generalisable to other regions in France, in particular rural areas where availability of high quality, specialist services is less than those in Paris, is difficult to know. The question of generalisability of our results to other countries in Europe or elsewhere is also an open one and requires further study.

are in many cases treatable. Nevertheless, and despite considerable progress in medical and surgical management of CHDs over the past three decades, CHDs remain a major cause of mortality and morbidity of perinatal origin and the first cause of infant death by malformation. ${ }^{1-4}$

Prenatal diagnosis and optimal postnatal management can result in secondary 
prevention of mortality and morbidity and improved long-term outcomes of newborns with $\mathrm{CHD} .{ }^{5-9}$ Indeed, previous studies have found that prenatal diagnosis can improve the chances of survival for newborns with certain types of CHD; this has been particularly the case for the transposition of great arteries (d-TGA) where studies in France as well as in the USA and the UK have found a higher survival for newborns with a prenatal diagnosis of their CHD. For other, very severe CHDs, including hypoplastic left heart syndrome, the results have not been consistent; ${ }^{6} 10-15$ whereas some studies have found a survival advantage associated with prenatal diagnosis, others have not found this to be the case.

Limited population-based data are available on the CHD in general and on the association between prenatal diagnosis and mortality in particular. ${ }^{6} 1416$ Indeed, by far most of the existing literature is based on studies in specialised centres. This paucity of population-based data in turn complicates the interpretation of the existing literature as outcomes from specialised centres may not reflect those in the population of patients as a whole and be subject to transfer and/or survival bias. In addition, the mortality outcomes assessed are often limited to short-term, postsurgical mortality whereas longer-term mortality such as the overall infant (up to 1 year) mortality has been assessed much less frequently.

Using data from a large, prospective, population-based cohort (EPIdémiologie des CARDiopathies congénitales (EPICARD)) study, we assessed the probability of prenatal diagnosis and the impact of prenatal diagnosis on the risk of infant (until 1 year of age) mortality for newborns with four major CHDs, the tetralogy of Fallot (TOF), the coarctation of aorta (CoA), d-TGA and functionally univentricular heart (FUH).

\section{MATERIALS AND METHODS}

\section{Data source}

We used data from the EPICARD Study, which is a population-based, prospective cohort study with long-term follow-up of all children with a CHD born to women in the Greater Paris area (Paris and its surrounding suburbs). All cases (live births, terminations of pregnancy for fetal anomaly (TOPFA), fetal deaths) diagnosed in the prenatal period or up to 1 year of age in the birth cohorts between 1 May 2005 and 30 April 2008 born to women residing in Greater Paris were eligible for inclusion. Diagnoses were confirmed in specialised paediatric cardiology departments and for the majority of TOPFA and fetal deaths by a standardised pathology examination. When a pathology exam could not be done the diagnoses were confirmed by a paediatric cardiologist (LH) and a specialist in echocardiography (J-MJ) in the EPICARD Study group, using the results of prenatal echocardiography examination.

Multiple sources of data including all maternity units, paediatric cardiology and cardiac surgery centres, fetal and neonatal pathology departments, neonatal and paediatric intensive units, infant units and outpatient clinics in Greater Paris and a neighbouring tertiary care centre were regularly consulted to attain completeness of case registrations. Informed consent was obtained from study participants. The last cases included in the study were those in the 2008 birth cohort who were diagnosed in 2009. Follow-up of children in the EPICARD cohort is now completed and included assessment of children's health and neurodevelopmental outcomes until 8 years of age.

Details of coding and classification of cases for the EPICARD Study are given elsewhere. ${ }^{17}$ Briefly, two paediatric cardiologists in the EPICARD Study group (LH, DB) attributed by consensus to each case, one, or in less than $20 \%$ of cases, two or up to six, six-digit code(s) of the long list of the International Paediatric and Congenital Cardiac Code. ${ }^{18}$

In order to identify 'isolated' cases of each of the four CHDs, we first excluded all cases that were associated with chromosomal anomalies and/or anomalies of other systems, including syndromes (see figure 1). In addition, when two or more of the four specific CHDs were present for the same fetus, we used the following hierarchical decision rule to classify the fetus as one and only one of the four CHDs in the study. The hierarchical order was as follows: FUH, d-TGA, TOF and CoA. Hence, fetuses in the study population with an FUH were classified as FUH regardless of any other associated anomalies. Those with TGA were classified as TGA except when FUH was also present. Those with TOF were classified as such (no other of the specific CHDs were present). Finally, fetuses with CoA were classified as such when none of the other three CHDs was also present.

\section{Study population}

Figure 1 shows the flow diagram for the selection of our study population. Overall, after excluding cases associated with chromosomal or other non-cardiac anomalies, including syndromes, our study population comprised 354 cases (live births, fetal deaths and terminations of pregnancy for fetal anomaly (TOPFA)), including 60 cases of tetralogy of Fallot (TOF), 77 coarctation of aorta (CoA), 85 TGA and 132 FUH.

\section{Statistical analysis}

For each of the four CHD, congenital heart defect (CHDs), we calculated the proportion of cases with a prenatal diagnosis, TOPFA and infant mortality with $95 \%$ binomial exact CIs. We conducted a Mantel-Haenszel analysis to test the association between prenatal diagnosis and probability of mortality and tested whether the association of prenatal diagnosis with mortality varied across the four CHDs by the test of homogeneity of risk ratios.

\section{RESULTS}

Table 1 shows the probability of prenatal diagnosis and TOFA for the four CHDs. Approximately, 95\% of FUH ( $95 \%$ CI 89.4 to 97.8 ), $71 \%$ of TGA ( $95 \%$ CI 59.7 to 80.0 ), 


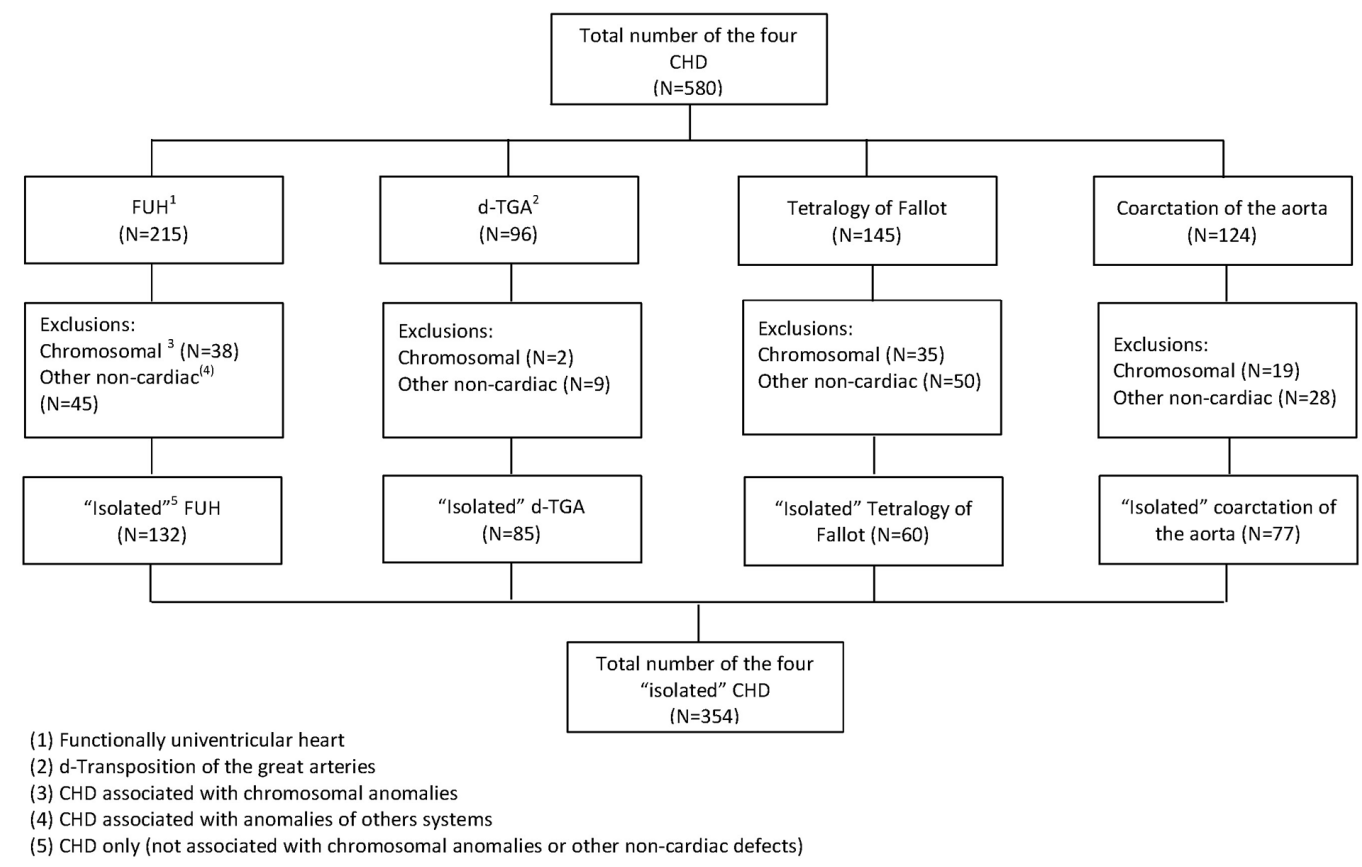

Figure 1 Flow chart for the study population.

$68 \%$ of TOF $(95 \%$ CI 55.0 to 79.7$)$ and $43 \%$ of CoA (95\% CI 31.6 to 54.6) were prenatally diagnosed (table 1). Among the prenatally diagnosed cases of FUH, about $70 \%$ (95\% CI 61.6 to 78.2) had a TOPFA; this proportion was approximately $3 \%$ for TGA, $12 \%$ for TOF and $9 \%$ for CoA (table 1).

Table 2 shows the outcomes of pregnancy for the four specific CHDs among all fetuses. Live births accounted for more than $90 \%$ of TGA, TOF and CoA, whereas less than a third of FUH were born alive. TOPFA comprised $67 \%$ of all fetuses with FUH, $2 \%$ of fetuses with TGA, $8 \%$ of those with TOF and $4 \%$ of cases with FUH. Stillbirths accounted for about $4 \%$ of FUH and $2 \%$ of TGA, TOF and CoA.

Table 3 shows the relation between infant mortality and prenatal diagnosis for the four CHDs. Overall, we found no statistical evidence of a lower risk of mortality for cases that were prenatally diagnosed (Mantel-Haenszel combined risk ratio $1.1,95 \%$ CI 0.5 to 2.2 ). The risk ratios of an infant death for prenatally diagnosed versus postnatally diagnosed cases were: 1.2 (95\% CI 0.5 to 3.1) for FUH, 2.1 (95\% CI 0.3 to 17.1 ) for TGA, 0.3 (95\% CI 0.02 to 2.6) for TOF and
$1.0(95 \%$ CI 0.2 to 5.7) for CoA. We found no statistically significant differences in the association between the risk of mortality and prenatal diagnosis across the four CHDs (test of homogeneity of risk ratios, $\mathrm{p}=0.6$ ).

\section{DISCUSSION}

Using prospective, population-based cohort data on 354 newborns with CHD, including FUH, d-TGA, TOF and CoA, we found that a considerable proportion of all cases were prenatally diagnosed. FUH, which can be diagnosed with the routine four-chamber view, had the highest probability of prenatal diagnosis $(\sim 95 \%)$ whereas those that need visualisation of the arterial trunks had a lower probability of prenatal diagnosis, particularly in the case of CoA $(-50 \%)$ whereas for TGA and TOF more than two-thirds of the cases had a prenatal diagnosis.

Looking at the association between timing of (prenatal vs postnatal) diagnosis of CHD and risk of infant mortality, we did not find a statistically significant survival advantage associated with prenatal diagnosis for the four

Table 1 Prenatal diagnosis for four specific congenital heart defects (CHDs), EPIdémiologie des CARDiopathies congénitales (EPICARD) Population-Based Cohort Study

\begin{tabular}{|c|c|c|c|c|c|}
\hline \multirow[b]{2}{*}{ CHD } & \multicolumn{3}{|c|}{ Prenatal diagnosis* } & \multicolumn{2}{|c|}{$\%$ TOPFA† } \\
\hline & $\mathbf{n}$ & $\%$ & $95 \% \mathrm{Cl}$ & $\%$ & $95 \% \mathrm{Cl}$ \\
\hline Functionally univentricular heart* & 132 & 94.7 & 89.4 to 97.8 & 70.4 & 61.6 to 78.2 \\
\hline Tetralogy of Fallot* & 60 & 68.3 & 55.0 to 79.7 & 12.2 & 4.1 to 26.2 \\
\hline Coarctation of the aorta* & 77 & 42.9 & 31.6 to 54.6 & 9.1 & 1.9 to 24.3 \\
\hline
\end{tabular}

${ }^{*}$ Cases with the specific International Paediatric and Congenital Cardiac Code for the given CHD, whether or not other CHD codes were also included; all cases with chromosomal or others anomalies were excluded.

†Terminations of pregnancy for fetal anomaly (TOPFA) among prenatally diagnoses cases. 
Table 2 Pregnancy outcomes for four specific congenital heart defects (CHDs), EPIdémiologie des CARDiopathies congénitales (EPICARD) population-based cohort study

\begin{tabular}{|c|c|c|c|c|c|c|c|}
\hline \multirow[b]{2}{*}{ CHD } & \multirow[b]{2}{*}{$\mathbf{N}$} & \multicolumn{2}{|c|}{ Live births } & \multicolumn{2}{|c|}{ TOPFA* } & \multicolumn{2}{|c|}{ Stillbirths } \\
\hline & & $\%$ & $95 \% \mathrm{Cl}$ & $\%$ & $95 \% \mathrm{CI}$ & $\%$ & $95 \% \mathrm{CI}$ \\
\hline Functionally univentricular heart $†$ & 132 & 29.5 & 21.9 to 38.1 & 66.7 & 57.9 -to 74.6 & 3.8 & 1.2 to 8.6 \\
\hline Tetralogy of Fallot† & 60 & 90.0 & 79.5 to 96.2 & 8.3 & 2.8 to 18.4 & 1.7 & 0.04 to 8.9 \\
\hline Coarctation of the aorta $\uparrow$ & 77 & 94.8 & 87.2to 98.6 & 3.9 & 0.8 to 11.0 & 1.3 & 0.03 to 7.0 \\
\hline
\end{tabular}

${ }^{*}$ Terminations of pregnancy for fetal anomaly (TOPFA) among the overall number of cases (ie, number of TOPFA divided by the total number of cases).

†Cases with the specific International Paediatric and Congenital Cardiac Code for the given CHD, whether or not other CHD codes were also included, all cases with chromosomal or others anomalies were excluded.

CHDs examined. Notwithstanding the limitations of the study and the caveats noted below, our findings suggest that in the current era, the beneficial effects of prenatal diagnosis in optimising prenatal and postnatal care of the newborns may be manifested, and hence should be looked for, in more 'subtle' or long-term outcomes, particularly those related to specific neurodevelopmental outcomes of the newborns with CHD. ${ }^{19} 20$

Our study has certain limitations. Despite the large size of our population-based cohort, the number of deaths for TGA, TOF and CoA was relatively small reflecting the high survival rates of newborns with these three CHDs. Therefore, the CIs for our risk ratio estimates for the relation between prenatal diagnosis and risk of mortality for each CHD were relatively wide and hence we may have missed an effect associated with prenatal diagnosis due to limited precision of estimates. This may have been particularly the case for TOF where the point estimate for the risk ratio suggested a lower risk of mortality for cases that were prenatally diagnosed but that this difference was not statistically significant. For the other three CHDs, the corresponding risk ratios were close to or higher than the null value. This suggests in turn that at least for FUH,
TGA and CoA, the lack of a statistically significant association between prenatal diagnosis and risk of mortality may reflect the absence of relation between prenatal diagnosis and mortality. This may be due to the fact that with the improvements in postnatal care, the risk of mortality is nowadays low for these 'curable' CHDs (TOF, TGA and CoA) regardless of the timing of diagnosis. In the case of FUH, there remains a high risk of infant mortality whether or not the cases were prenatally diagnosed.

However, in addition to a relatively small sample size for individual CHD which may have resulted in lack of statistically significant results, an important caveat should be considered in interpreting our results on the relation between prenatal diagnosis and risk of mortality. It is at least possible that even in the case of an individual, well characterised defect, those that are prenatally diagnosed may be more severe than those diagnosed later. Hence, finding a survival advantage in relation to prenatal diagnosis, as has been found to be the case particularly for TGA in previous studies, may represent the 'lower limit' of the advantage that may be attributed to prenatal diagnosis, which can lead to a more optimal postnatal clinical and surgical management of CHD. Along the same lines,

Table 3 Association between prenatal diagnosis and risk of infant mortality for four specific congenital heart defects (CHDs), EPIdémiologie des CARDiopathies congénitales (EPICARD) Population-Based Cohort Study

\begin{tabular}{|c|c|c|c|c|c|c|c|}
\hline \multirow[b]{2}{*}{ CHD } & \multicolumn{3}{|c|}{ Prenatal diagnosis } & \multicolumn{2}{|c|}{ Infant mortality } & \multirow[b]{2}{*}{ Risk ratio } & \multirow[b]{2}{*}{$95 \% \mathrm{Cl}$} \\
\hline & & $\mathrm{n}^{*}$ & n† & $\%$ & $95 \% \mathrm{Cl}$ & & \\
\hline \multirow[t]{2}{*}{ Functionally univentricular heart } & No & 7 & 3 & 42.9 & 9.9 to 81.6 & & \\
\hline & Yes & 32 & 17 & 53.1 & 34.7 to 70.9 & 1.2 & 0.5 to 3.1 \\
\hline \multirow[t]{2}{*}{ d-Transposition of the great arteries $\neq$} & No & 24 & 1 & 4.2 & 0.1 to 21.1 & & \\
\hline & Yes & 57 & 5 & 8.8 & 2.9 to 19.3 & 2.1 & 0.3 to 17.1 \\
\hline \multirow[t]{2}{*}{ Tetralogy of Fallotł } & No & 18 & 2 & 11.1 & 1.4 to 34.7 & & \\
\hline & Yes & 36 & 1 & 2.8 & 0.07 to 14.5 & 0.3 & 0.02 to 2.6 \\
\hline \multirow[t]{2}{*}{ Coarctation of the aortał } & No & 44 & 3 & 6.8 & 1.4 to 18.7 & & \\
\hline & Yes & 29 & 2 & 6.9 & 0.8 to 22.8 & 1.0 & 0.2 to 5.7 \\
\hline
\end{tabular}

${ }^{*} \mathrm{~N}=$ number of live births (denominator data).

$\dagger \mathrm{n}=$ number of deaths (numerator data).

¥Cases with the specific International Paediatric and Congenital Cardiac Code for the given CHD; whether or not other CHD codes were also included, all cases with chromosomal or others anomalies were excluded. 
lack of a survival advantage, may be due to an adverse selection bias for cases diagnosed prenatally. This "negative' finding can hence be misleading as the absence of an effect associated with prenatal diagnosis, would actually indicate that prenatal diagnosis improves survival.

We also conducted an exploratory analysis (detailed results available from authors) to look at the possible effects of cardiac anomalies that may have been associated with the four CHDs in our study.

Specifically, we looked separately at each of the four CHDs when they were completely isolated, that is, when there were no cardiac anomalies present other than the four CHDs themselves versus when they were associated with other cardiac defects (note that cases with non-cardiac defects, including syndromes as well as chromosomal anomalies had already been excluded).

In general, when the defect was completely isolated the risk of mortality was lower than when the defect was associated with other cardiac anomalies. However, the relation between prenatal diagnosis and risk of mortality was not appreciably different for the completely isolated cases versus those associated with other cardiac anomalies. It should be noted that this stratified analysis can at best be considered exploratory as the number of events (deaths) in each group were quite small.

Nevertheless, the results of this analysis make clinical sense. Even though we did not look specifically at postoperative mortality, associated cardiac anomalies can in particular render the surgical interventions more complex, which can in turn explain at least some of the higher risks of mortality in the group of defects associated with other cardiac anomalies.

Our findings reflect population-based data from the Greater Paris area. In our region, the organisation of prenatal diagnostic services is well codified and includes in particular the constitution of 48 multidisciplinary centres for prenatal diagnosis across the country, including 4 in Paris and 5 in its surrounding suburbs. By law, the severity of the fetal anomaly must be certified by two experts from these centres in order for TOPFA to be authorised. For cases in which either TOPFA is not an appropriate decision ('curable' or not sufficiently severe anomalies) or for which women opt to continue their pregnancy even if the experts consider that TOPFA is an acceptable option, the centres play an important role in the perinatal management of cases to optimise care for both mothers and their affected newborns. Mandates for the exclusive coordination of prenatal diagnosis services by these multidisciplinary centres are likely to have contributed to a wider availability of high-quality prenatal diagnostic services in our population. Moreover, there is a high concentration of specialised services for postnatal care of newborns with CHD, including Neonatal Intensive Care Units (NICUs), Paediatric Intensive Care Units (PICUs) and cardiac surgery centres. This, in turn, has the effect that the time required for transfers (due to relative geographical proximity) is generally not very long even if we did not specifically address this question in our study. Hence, even cases with postnatal diagnosis can usually be transferred to tertiary, specialised centres for optimal care. Therefore, the effect of prenatal diagnosis may be relatively lower in our population versus one in say urban areas or in general when one or only a few tertiary centres are available for transfer of patients with CHD. Finally, it is worth noting that, at least for the time being, routine pulse oximetry is not practised in France. There is, however, an ongoing study in the Aquitaine area for looking at the impact of pulse oximetry for newborns with CHD.

Given these considerations, the extent to which our results may be generalisable to other regions in France, in particular rural areas where availability of high quality, specialist services is less than those in Paris, is difficult to know. The question of generalisability of our results to other countries in Europe or elsewhere is also an open one and requires further study.

We should emphasise that interpreting these results as proof for a general lack of efficacy of prenatal diagnosis for optimal management and outcomes of CHD would clearly be misguided and misleading. Instead, our results imply that survival may no longer be the most relevant outcome, or the best criterion, for evaluating the impact of prenatal diagnosis on outcomes of CHD. Indeed, as recent studies have shown, prenatal diagnosis can improve the neurodevelopmental outcomes of newborns with CHD, for example, in case of TGA. ${ }^{19-22}$ What is needed now is to assess whether these results that are based on hospital-based studies from specialised centres also hold at the population level and for other CHDs. It would also be worthwhile to see whether prenatal diagnosis may continue to be associated with better survival outcomes in settings where specialised services are not readily available and require in utero or early transfer of newborns to distant referral centres. Moreover, the underlying clinical and pathophysiological mechanisms that may explain the beneficial effects of prenatal diagnosis on outcomes of newborns with CHD require further study. ${ }^{23}$

\section{Author affiliations}

${ }^{1}$ INSERM UMR 1153, Obstetrical, Perinatal and Pediatric Epidemiology Research Team (EPOPé), Center for Epidemiology and Statistics, Sorbonne Paris Cité (CRESS), DHU Risks in Pregnancy, Paris Descartes University, Paris, France

${ }^{2}$ Congenital heart defects surgery unit, Marie Lannelongue Hospital, Le Plessis Robinson, France

${ }^{3}$ Complex Congenital Heart Defects Reference Center - M3C-Necker, Paris Descartes University, Paris, France

${ }^{4}$ Centre Pluridisciplinaire de Diagnostic Prénatal, UPMC, Hôpital Trousseau, Paris, France

${ }^{5}$ Maternité de Port-Royal, Groupe Hospitalier Cochin-Broca-Hôtel Dieu, Université Paris Descartes, Paris, France

Acknowledgements BK and NL had full access to the data and take responsibility for the integrity of the data and the accuracy of the data analysis. The EPICARD study was approved by the French National Committee of Information and Freedom (Commission nationale de l'informatique et des libertés).

Collaborators Principal Investigators: François Goffinet, Babak Khoshnood Steering Committee: Damien Bonnet (Hôpital Necker Enfants Malades, AP-HP, Centre de référence M3C, Université Paris Descartes, Paris) Drina Candilis (Université Paris-Diderot, Paris) Anne-Lise Delezoide (Hôpital Robert Debré, AP-HP, Service de biologie du Développement, Université Paris-Diderot, Paris) François 
Goffinet (Groupe Hospitalier Cochin-Hôtel Dieu, AP-HP, Maternité Port-Royal et INSERM U1153, Equipe EPOPé, Université Paris Descartes, Paris) Lucile Houyel (Hôpital Marie Lannelongue, Service de chirurgie des cardiopathies congénitales, Le Plessis-Robinson) Jean-Marie Jouannic (Hôpital Trousseau, AP-HP, Centre pluridisciplinaire de diagnostic prénatal, UPMC, Paris) Babak Khoshnood (INSERM U1153, Equipe EPOPé, Paris)Nathalie Lelong (INSERM U1153, Equipe EPOPé, Paris) Suzel Magnier (Hôpital Robert Debré, AP-HP, Service de cardiologie, Paris) JeanFrançois Magny (Hôpital Necker Enfants Malades, AP-HP, Service de néonatologie, Paris) Caroline Rambaud (Hôpital Raymond Poincarré, AP-HP, Service d'anatomie et cytologie pathologiques - Médecine légale, UVSQ, Garches) Dominique Salomon (INSERM U1153, Equipe EPOPé, Paris) Johanna Calderon (INSERM U1153, Equipe EPOPé, Paris) Project Coordination and Data Analysis Committee: François Goffinet, Babak Khoshnood, Nathalie Lelong, Thibaut Andrieu, Anne-Claire Thieulin, Véronique Vodovar Independent Data Monitoring Committee (URC Paris Centre et CIC Cochin Necker Mère Enfant) :Maggy Chausson, Anissa Brinis, Laure Faure, Maryline Delattre, Jean-Marc Treluyer (Groupe Hospitalier Cochin-Hôtel Dieu, AP-HP, Université Paris Descartes, Paris) External Scientific Committee: Gérard Bréart, Dominique Cabrol, Alain Sérraf, Daniel Sidi, Marcel Voyer Participating Centers: The Greater Paris Area (Paris and its surrounding suburbs) public (AP-HP) and private maternity units,Departments of Pediatric Cardiology and Pediatric Cardiac Surgery, pediatric cardiologists in private practice, Neonatal Intensive Care Units, Pediatric Intensive Care Units, Emergency Transfer Services (SMUR), Departments of Pathology, Sudden Death Centers, Departments of Family and Infant Protection (DFPE)

Contributors FG and BK are the principal investigators of this study, had full access to the data, and take responsibility for the integrity of the data and the accuracy of the data analysis. BK and FG conceived the study. NL and BK conducted the statistical analysis with the assistance of MB and in consultation with FG. LH, $\mathrm{DB}$ and J-MJ provided clinical expertise. BK wrote the first draft of the article. All coauthors made substantial contributions to the interpretation of results and revisions of the manuscript.

Funding This work was supported by two grants from the French Ministry of Health (PHRC 2004 and 2008). Additional funding was provided by the AREMCAR (Association pour la Recherche et l'Etude des Maladies Cardiovasculaires) association.

Competing interests None declared.

Ethics approval The EPICARD study was approved by the French National Committee of Information and Freedom (Commission nationale de l'informatique et des libertés).

Provenance and peer review Not commissioned; externally peer reviewed. Data sharing statement № further data are available.

Open Access This is an Open Access article distributed in accordance with the Creative Commons Attribution Non Commercial (CC BY-NC 4.0) license, which permits others to distribute, remix, adapt, build upon this work non-commercially, and license their derivative works on different terms, provided the original work is properly cited and the use is non-commercial. See: http://creativecommons.org/ licenses/by-nc/4.0/

(c) Article author(s) (or their employer(s) unless otherwise stated in the text of the article) 2017. All rights reserved. No commercial use is permitted unless otherwise expressly granted.

\section{REFERENCES}

1. Dolk H, Loane M, Garne E. Congenital heart defects in Europe: prevalence and perinatal mortality, 2000 to 2005 . Circulation 2011;123:841-9.

2. Lee K, Khoshnood B, Chen L, et al. Infant mortality from congenital malformations in the United States, 1970-1997. Obstet Gynecol 2001;98:620-7.

3. EUROCAT Central Registry UoU. EUROCAT Special Report: Congenital Heart Defects in Europe 2000-2005. 2009 http://www. eurocat-network.eu/content/Special-Report-CHD.pdf.
4. Khoshnood B, Lelong N, Houyel L, et al. Prevalence, timing of diagnosis and mortality of newborns with congenital heart defects: a population-based study. Heart 2012;98:1667-73.

5. Bonnet D, Coltri A, Butera G, et al. Detection of transposition of the great arteries in fetuses reduces neonatal morbidity and mortality. Circulation 1999;99:916-8.

6. Khoshnood B, De Vigan C, Vodovar V, et al. Trends in prenatal diagnosis, pregnancy termination, and perinatal mortality of newborns with congenital heart disease in France, 1983-2000: a population-based evaluation. Pediatrics 2005;115:95-101.

7. Wernovsky G, Shillingford AJ, Gaynor JW. Central nervous system outcomes in children with complex congenital heart disease. Curr Opin Cardiol 2005;20:94-9.

8. Blyth M, Howe D, Gnanapragasam J, et al. The hidden mortality of transposition of the great arteries and survival advantage provided by prenatal diagnosis. BJOG 2008;115:1096-100.

9. Calderon J, Angeard N, Moutier S, et al. Impact of prenatal diagnosis on neurocognitive outcomes in children with transposition of the great arteries. J Pediatr 2012;161:94-8.

10. Holland BJ, Myers JA, Woods CR. Prenatal diagnosis of critical congenital heart disease reduces risk of death from cardiovascular compromise prior to planned neonatal cardiac surgery: a metaanalysis. Ultrasound Obstet Gynecol 2015;45:631-8.

11. Kumar RK, Newburger JW, Gauvreau K, et al. Comparison of outcome when hypoplastic left heart syndrome and transposition of the great arteries are diagnosed prenatally versus when diagnosis of these two conditions is made only postnatally. Am J Cardiol 1999;83:1649-53.

12. Mahle WT, Clancy RR, McGaurn SP, et al. Impact of prenatal diagnosis on survival and early neurologic morbidity in neonates with the hypoplastic left heart syndrome. Pediatrics 2001;107:1277-82.

13. Tworetzky W, McElhinney DB, Reddy VM, et al. Improved surgical outcome after fetal diagnosis of hypoplastic left heart syndrome. Circulation 2001;103:1269-73.

14. Oster ME, Kim CH, Kusano AS, et al. A population-based study of the association of prenatal diagnosis with survival rate for infants with congenital heart defects. Am J Cardiol 2014;113:1036-40.

15. Li YF, Zhou KY, Fang J, et al. Efficacy of prenatal diagnosis of major congenital heart disease on perinatal management and perioperative mortality: a meta-analysis. World J Pediatr 2016;12:298-307.

16. Wright LK, Ehrlich A, Stauffer N, et al. Relation of prenatal diagnosis with one-year survival rate for infants with congenital heart disease. Am J Cardiol 2014;113:1041-4.

17. Houyel L, Khoshnood B, Anderson RH, et al. Population-based evaluation of a suggested anatomic and clinical classification of congenital heart defects based on the International Paediatric and Congenital Cardiac Code. Orphanet J Rare Dis 2011;6:64.

18. Franklin RC, Jacobs JP, Krogmann ON, et al. Nomenclature for congenital and paediatric cardiac disease: historical perspectives and The International Pediatric and Congenital Cardiac Code. Cardiol Young 2008;18(Suppl 2):70-80.

19. Calderon J, Bonnet D, Courtin C, et al. Executive function and theory of mind in school-aged children after neonatal corrective cardiac surgery for transposition of the great arteries. Dev Med Child Neurol 2010;52:1139-44.

20. Calderon J, Angeard N, Moutier S, et al. Impact of prenatal diagnosis on neurocognitive outcomes in children with transposition of the great arteries. J Pediatr 2012;161:94-8.

21. Calderon J, Jambaqué I, Bonnet D, et al. Executive functions development in 5- to 7-year-old children with transposition of the great arteries: a longitudinal study. Dev Neuropsychol 2014;39:365-84.

22. Calderon J, Angeard N, Pinabiaux C, et al. Facial expression recognition and emotion understanding in children after neonatal open-heart surgery for transposition of the great arteries. Dev Med Child Neurol 2014;56:564-71.

23. Peyvandi S, De Santiago V, Chakkarapani E, et al. Association of Prenatal Diagnosis of Critical Congenital Heart Disease With Postnatal Brain Development and the Risk of Brain Injury. JAMA Pediatr 2016;170:e154450. 